\title{
Gilles Lipovetsky, Jean Serroy (2010). A Cultura-Mundo. Resposta a uma sociedade desorientada. Lisboa: Edições 70
}

Alexandre Duarte*

A cultura transformou-se em mundo, em cultura-mundo, a cultura-mundo do tecnocapitalismo planetário, das indústrias culturais, do consumismo total, dos media e das redes digitais. (p. 11)

O mote para uma interpretação crítica, objectiva e muito pertinente da sociedade actual, que o autor apelida de hipermoderna, é feito logo nas primeiras páginas deste livro e dá ao leitor uma visão perfeitamente lúcida dos paradigmas com que o mundo se debate nos dias de hoje. Dividida em quatro grandes áreas de análise - a saber, mercado, comunicação, mitos e desafios e civilização -, esta cultura-mundo "designa a época da expansão assombrosa do universo da comunicação, da informação e da mediatização” (p. 14).

Começando por estabelecer uma cronologia evolutiva das relações entre a cultura e o todo social, o autor identifica três grandes fases. Na primeira, a cultura surge ligada aos aspectos religioso-tradicionais, e não pode ser separada das suas interdependências políticas, mágicas, religiosas, parentais ou entre clãs. Passada de geração em geração, esta cultura não reconhece o individualismo e perpetua-se legitimada pela força e poderes do invisível. Uma segunda época coincide com o surgimento das democracias modernas e rasga definitivamente com o até então estabelecido. Substituindo a religião pela ciência, a tradição pelo progresso, o inquestionável pela racionalidade e o sobrenatural inatingível pela afirmação do ser humano enquanto verdadeiro motor da civilização e construção do mundo e do futuro, esta segunda fase distingue claramente uma arte "comercial" dirigida às massas e ao sucesso imediato, em função das tendências e os gostos momentâneos do público, de uma outra forma de arte, mais pura, mais elevada e que recusa a mercantilização e a banalização, regendo-se por leis próprias e autónomas. Finalmente, nas últimas duas ou três décadas, o mundo entrou, segundo o autor, numa nova fase, caracterizada pela substituição de uma valorização do futuro pelo sobreinvestimento do presente, do imediato, do já.

Impulsionada pelo individualismo exacerbado - tema que o autor revisita depois de o ter abordado em anteriores obras como A Era do Vazio (Lipovetsky, 1989) ou O Império do Efémero (Lipovetsky, 2010) -, esta nova forma de cultura é ditada, moldada e multiplicada pela exigência e urgência da economia que, ao pensá-la em termos de mercado, de rentabilidade, de racionalização, de volume e de lucros, a transforma numa commodity $^{1}$. A anterior oposição entre alta e baixa cultura desaparece numa homoge-

\footnotetext{
* Professor Assistente da Escola Superior de Marketing e Publicidade do IADE, Investigador da UNIDCOM, unidade de I\&D e Doutorando em Ciências da Comunicação na Universidade do Minho (ale@kanguru.pt).

${ }^{1}$ Palavra utilizada no universo do marketing para designar um produto indispensável ao dia-a-dia, de que são exemplos a água ou a electricidade, para citar apenas dois.
} 
neização cultural que tudo alinha e padroniza em função dos interesses capitalistas. Esta cultura global, cada vez mais igual e acessível devido à voracidade dos mercados e à expansão das redes de comunicação, é desta forma marcada pela compressão do tempo e pelo encurtamento do espaço.

Mas, apesar do hiperindividualismo, da exigência constante de liberdade e igualdade, da superabundância de informação e da ligação permanente ao mundo e aos outros, o ser humano encontra-se perdido, desorientado, confuso e inseguro. "A incerteza tornou-se a coisa mais presente do mundo" (Lipovetsky \& Serroy, 2010: 28) onde o caos emocional se deve não à escassez, mas ao excesso, ao hiper.

E hiper é definitivamente o conceito-chave desta obra, que define a organização deste mundo hipermoderno em redor dos seguintes quatro pólos estruturantes: hiperindividualismo (o culto do eu, liberto já do passado constrangimento comunitário), hipercapitalismo (resultado da globalização financeira), hipertecnicização (a exaltação da técnica e da tecnologia ao serviço do Homem) e hiperconsumo (a consagração do hedonismo através da aquisição de bens e serviços).

Esta nova dinâmica social, que o autor define como cultura-mundo, é analisada nesta obra em redor de duas dimensões: enquanto sistema agregador e organizador do mundo e, por outro lado, representando a totalidade de conteúdos produzidos, vendidos e consumidos em todo o planeta.

O hipercapitalismo, com a sua crescente importância, é mais do que económico, é também cultural, a partir do momento em que invadiu todas as esferas da nossa vida, dos objectos aos pensamentos, da arte à educação, dos valores aos relacionamentos.

Do ponto de vista tecnológico, o desenvolvimento constante e acelerado de novas formas técnicas transformou a própria forma de ver, pensar e sentir dos seres humanos. A comunicação aumenta exponencialmente a cada dia que passa mas, curiosamente, no sentido contrário aos encontros: "O corpo deixa de ser a âncora real da vida, e vai-se formando um universo sem corpo, dessensualizado e desrealizado: o dos ecrãs e dos contactos digitais" (p. 57). É deste ponto de partida que o autor chama a atenção para o novo estádio de evolução da espécie humana a que deu o nome de homo ecranis. Um mundo e uma vivência onde tudo é visto e partilhado através de ecrãs: dos monitores médicos ao cinema, da televisão ao GPS, das consolas aos telemóveis. Ao ponto de nada existir sem a partilha. Se não foi visto, se não pode ser mostrado, se as massas não têm acesso, então é como se não existisse. Este mundo dos ecrãs que acompanham o homem desde o nascimento até à sua morte desregulou as relações de espaço e tempo, ao permitir o acesso a praticamente toda a informação, em tempo real, do ponto mais cosmopolita ao mais remoto do planeta e de forma total, ainda que muitas vezes de maneira não ordenada, hierarquizada ou fiável.

Nesta cultura-mundo, onde tudo é efémero, tudo é descartável, tudo é transitório na permanente e ansiosa expectativa do seguinte, da próxima novidade, da "next big thing”, o hiperconsumidor, ao mesmo tempo que procura bem-estar, divertimento e a satisfação imediata, perde os valores e as referências, perde as certezas e a fé. Neste ponto, o autor retoma a sua tese avançada na obra A Era do Vazio, onde escreve: 
A contradição nas nossas sociedades não resulta apenas do fosso entre a cultura e a economia, resulta do próprio processo de personalização, de um processo sistemático de atomização e de individualização narcísica: quanto mais a sociedade se humaniza, mais o sentimento de anonimato se estende; quanto mais há indulgência e tolerância, mais aumenta a falta de segurança do indivíduo em relação a si próprio (...) quanto mais a comunicação e o diálogo se institucionalizam, mais sós se sentem os indivíduos, e com maiores dificuldades de contacto; quanto mais cresce o bem-estar, mais a depressão triunfa. (Lipovetsky, 1989: 119)

Paralelamente, há um outro dado novo e pertinente que define esta cultura-mundo: da moda à música, da literatura ao teatro, da pintura ao espectáculo, são agora os media que fabricam as estrelas, que as inventam, que as mostram e as promovem, tornando-se assim nos novos legitimadores culturais, com um poder cada vez maior sobre a vida intelectual e cultural ao darem, ou não, visibilidade aos projectos e às pessoas.

A globalização deu origem a um mundo cada vez mais igual, cada vez mais padronizado. A probabilidade de um jovem do México vestir, comer, ouvir as mesmas músicas, ver os mesmos filmes, assistir aos mesmos programas de televisão e ler os mesmos livros que um outro da Finlândia é cada vez maior.

A sociedade hipermoderna homogeneizou os produtos, as culturas, e até os gostos, vontades, expectativas e ambições. Mas fê-lo de uma forma agregadora, i.e., as culturas partilham e cruzam elementos, ao mesmo tempo acolhendo e cedendo partes de si mesmas, numa troca permanente e inclusiva. Restaurantes mexicanos, tailandeses, chineses, italianos, japoneses estão lado a lado com as cadeias americanas de fast food, na maioria das capitais mundiais, para citar apenas um exemplo evidente. Esta cultura-mundo é pois uma amálgama de pequenos pedaços, um verdadeiro mosaico de retalhos.

E é neste mundo egoísta, individualista, centrado no culto do eu, da satisfação imediata, da rapidez, da espectacularidade e da imagem que as marcas ganham protagonismo e importância, assumindo-se como extensões dos indivíduos, classificando e dando a quem as ostenta o simbolismo por elas veiculados. As marcas representam estilos, personalidades, "falam" por quem as usa, e valem muito mais do que o seu custo de produção, devido à hipervalorização da sua dimensão imaterial em detrimento da funcionalidade própria do produto em causa. "O que o consumidor compra, antes de mais, é a marca e com ela um suplemento de alma, de sonho e de identidade” (p. 117).

Estas hipermarcas criaram uma cultura própria, uma cultura de marcas que ajudam os seus utilizadores a viver nesta dinâmica social desfragmentada, ao transmitirem pontos de referência e identidade, gerando sentimentos de pertença, de comunhão e, consequentemente, de integração.

É o marketing na sua exaltação máxima, integrando também ele, e de forma muito vincada, a cultura-mundo, através da construção de imagens, de sonhos, de um imaginário colectivo desejado e partilhado por indivíduos do mundo inteiro.

Da educação às sitcoms televisivas, dos chats às músicas, da arte à publicidade, da religião aos comportamentos, dos gostos aos desejos, nada escapa a esta "sociedade consumista-hedonista-neo-individualista da hipermodernidade" (pp. 186-187) que tudo abrange e abraça. 
No final desta obra, o autor aponta três imperativos para lidar com esta nova realidade: em primeiro lugar, a reabilitação da cultura do trabalho e do mérito, potenciando para isso a formação profissional, quer de base, quer contínua. Em segundo lugar, reforçando a coesão social, uma vez que a estabilidade, a protecção e a justiça social são fundamentais para o bom desempenho e consequente crescimento. E finalmente, a necessidade de se investir no capital humano, na educação e na investigação. Segundo o autor, a única forma de garantirmos um futuro mais promissor.

A nós, resta-nos sublinhar a pertinência e actualidade do tema desta obra, de tal forma que ela é, em si mesma, um produto desta hipersociedade: a sua publicação, divulgação, publicitação e venda em hipercatedrais de consumo em todo o mundo, provam toda a tese exposta.

\section{Referências bibliográficas}

Lipovetsky, G. \& Serroy, J. (2010) A Cultura-Mundo, Resposta a uma sociedade desorientada, Lisboa: Edições 70 .

Lipovetsky, G. (1989) A Era do Vazio, Lisboa: Relógio d'Água.

Lipovetsky, G. (2010) O Império do Efémero, (2. ${ }^{a}$ ed.) Lisboa: D. Quixote. 